\title{
MANFACTURING A TOMATO SEED EXTRCATING MACHINE
}

\author{
Ahmed M. I. Soliman", Mahmoud A. El-Nono ${ }^{* *}$, \\ Mubark M. Mustafa ${ }^{* *}$ and El-Amin M. Arif ${ }^{* * * *}$
}

\begin{abstract}
Manual extraction of tomato seed is a tedious operation and has some drawbacks such as incentive labor, excessive water use and much time consuming. Therefore, this study was dedicated to address the problems of manual extraction via manufacturing a simple machine to extract tomato seeds. Some of physical and mechanical properties of tomato fruits and seeds were measured. After that, an electric-motor powered machine was fabricated and followed by a techno-economic to investigate the potential effects of the machine operating parameters, namely, separating drum speed, feeding rate and drum with holes diameter on the machine evaluative criteria, namely, extractor productivity, extractor efficiency, seed purity, seed losses percentage and specific energy consumption. The analysis of data showed running the machine at the drum speed of $15.71 \mathrm{~m} / \mathrm{s}$ (600 rpm), feeding the machine with $150 \mathrm{~kg} / \mathrm{h}$ of tomato fruits and selecting the drum with holes diameter of $5 \mathrm{~mm}$ attained the following results to operate the developed machine economically: extractor productivity (9.12 kg/h), extractor efficiency (96.80\%), seed purity (92\%), seed losses percentage (3.20\%) and specific energy requirement $(0.042 \mathrm{~kW} . \mathrm{h} / \mathrm{kg})$. Germination tests proved that the mechanical extraction of seeds did not harm the germinabilty of seeds as compared to the manual method. Lastly, the cost of manual process rose by about 42 and $182 \%$ in comparison with the cost of mechanical system before and after discounting pulp tomato revenue, respectively.
\end{abstract}

\section{INTRODUCTION}

7 Tomatoes, Lycopersicum esculentum Mill, are among the largest vegetable crops in Egypt. According to the latest statistics

provided by FAO (2016), Egypt was the fifth world producer of tomatoes with $6 \%$ of the total world production (1993-2013).

\footnotetext{
*Assistant Researcher, Agric. Eng. Res. Inst. (AEnRI), Agric. Res. Cen.

** Professor Emeritus, Agric. Eng. Dep., Fac. of Agric., Ain Shams Uni.

${ }^{* * * *}$ Head Researcher, Agric. Eng. Res. Inst. (AEnRI), Agric. Res. Cen.
} 
When comparing the tomatoes production in 2013 in terms of quantity and dollar value to other agricultural products cultivated in the country, the tomato crop attained the fourth and first rank, respectively.

There are many factors having a major impact on the tomato production; seeds quality is one of them. The quality of seeds depends on many parameters such as harvesting, extracting, cleaning, transportation, and storage (McCormarck, 2010). Currently, tomato seeds are extracted by cutting and crushing the tomato fruits and then allowing the fruits to ferment in the solution of HCL for 12 to 24 hours. After partial fermentation, the pulp is washed repeatedly and seeds are collected. This method of seed production is highly labor intensive, tedious, time consuming, and produces a large effluent during the washing process (Kailappan, et al., 2005).

Several endeavors have been made to develop and evaluate tomato seed extracting machines. Kalra et al. (1983) developed a low cost manually operated tomato seed extractor. The evaluation of that extractor showed that the machine capacity, recovery percentage, and germination percent were $60 \mathrm{~kg} / \mathrm{h}, 1.07$ and $82 \%$, respectively.

Kailappan et al. (2005) fabricated equipment for extracting seeds from tomato fruit, and the developed extractor saved $96.6 \%$ in time and $89.6 \%$ in costs as compared to the manual method of seed extraction.

Gregg and Billups (2010) described one of the first successful tomato seed extraction machines was the seed thresher. The thresher could be towed behind a tractor to extract seed in the field, or used as a stationary extractor. It could also handle up to 3 - 4 tons of tomatoes per hour.

El-Iraqi et al. (2012) designed an extraction machine for tomato seeds. It was revealed that the highest value for seed and extraction efficiency $(95.02 \%)$ and cleaning efficiency $(86.12 \%)$ was recorded at $2.88 \mathrm{~m} / \mathrm{s}$ for the speed of crushing/separating drum, $8^{\circ}$ for the inclination angle of extraction machine, and $60 \mathrm{~kg} / \mathrm{h}$ for the feeding rate. The relationship between feeding rates and seed losses was positive.

The principal aim of this research was to manufacture a tomato seed extracting machine that may aid the seed producers in alleviating the problems of manual seed extraction. Hence, the following objectives were addressed: (A) Studying the physical and mechanical properties related to 
seed extraction; (B) Investigating the influences of the operational variables over mechanical seed extracting machine; and (C) Evaluating the machine, collecting data, and conducting the cost analysis.

\section{MATERIAL AND METHODS}

The experiments of the exiting study were conducted in 2016 at the Laboratory of Agricultural Engineering Research Institute (AEnRI), Giza, and the fabrication of tomato seed extracting machine was accomplished at a private workshop in Abou-Hammad city, Al-Sharkia governorate.

\subsection{Tomato fruits}

Tomato variety, named Hybrid GS 12, was used for all experiments in this study. For trails of physical and mechanical properties, 50 fruits were randomly selected and tested at room ambient temperature. Therefore, a number of physical and mechanical properties were measured for raw tomatoes and seeds as is shown in Table (1).

Table (1): Main characteristics of the tomato samples.

\begin{tabular}{|c|c|c|c|c|}
\hline Characteristic & Max. & Min. & AV. & SD \\
\hline \multicolumn{5}{|c|}{ Tomato fruit } \\
\hline \multicolumn{5}{|l|}{ Axial dimensions: } \\
\hline Height (mm) & 61.37 & 48.85 & 54.19 & 3.18 \\
\hline Major diameter (mm) & 70.52 & 51.16 & 61.88 & 3.68 \\
\hline Minor diameter (mm) & 64.68 & 49.86 & 57.40 & 3.19 \\
\hline Arithmetic mean diameter (mm) & 64.59 & 49.96 & 57.82 & 3.00 \\
\hline \multicolumn{5}{|l|}{ Mass: } \\
\hline Pulp mass percentage $(\%)$ & 81.45 & 61.61 & 74.15 & 4.45 \\
\hline Juice mass percentage $(\%)$ & 28.07 & 10.85 & 17.76 & 4.14 \\
\hline Seed mass percentage $(\%)$ & 14.29 & 3.70 & 8.09 & 2.16 \\
\hline Moisture content (w.b.), \% : & 96.87 & 95.92 & 96.16 & 0.17 \\
\hline \multicolumn{5}{|l|}{ Firmness: } \\
\hline Vertical axis $(\mathrm{N})$ & 39.24 & 31.20 & 34.88 & 2.48 \\
\hline Horizontal axis $(\mathrm{N})$ & 44.15 & 32.12 & 37.87 & 3.82 \\
\hline Coefficient of friction & 0.390 & 0.291 & 0.342 & 0.035 \\
\hline \multicolumn{5}{|c|}{ Tomato seed } \\
\hline \multicolumn{5}{|l|}{ Axial dimensions: } \\
\hline Length (mm) & 5.42 & 3.94 & 4.76 & 0.28 \\
\hline Width (mm) & 4.62 & 3.56 & 4.10 & 0.23 \\
\hline Thickness (mm) & 1.66 & 1.32 & 1.47 & 0.09 \\
\hline Arithmetic mean diameter (mm) & 3.87 & 2.94 & 3.44 & 0.18 \\
\hline Moisture content (w.b.), \% : & 93.43 & 91.81 & 92.02 & 0.26 \\
\hline
\end{tabular}




\subsection{Description of the extracting machine}

The fabricated machine made up of main frame, feed hopper, fruit cutting mechanism, delivery chute, seed separating mechanism, seed outlet, pulp discharge outlet and power transmission systems as shown in Fig. (1).
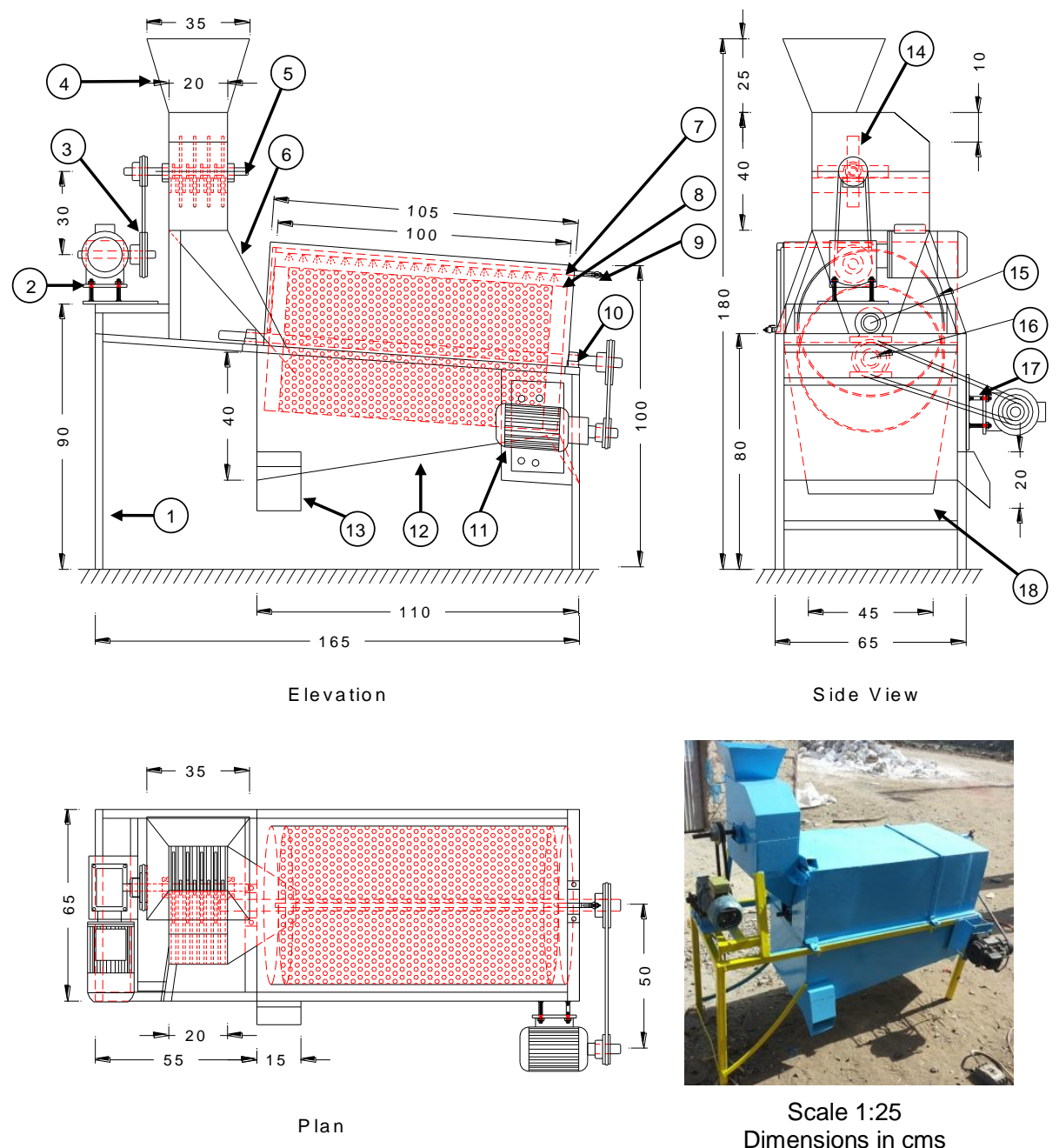

1. Main frame.

2. Electrical motor (0.5 hp).

10. Housing bear.

11. Electrical motor (1 hp).

3. V-belts for power transmission.

4. Feed hopper.

5. Cutting rotor shaft.

6. Delivery chute.

7. Upper cover of the drum.

8. Perforated pipe.

9. Tape water.

12. Lower cover of the drum.

13. Seed outlet.

14. Cutting bars.

15. Perforated separating drum.

16. Separating rotor shaft.

17. V-belts for power transmission.

18. Pulp discharge outlet

Fig. (1): The manufactured tomato seed extracting machine. 


\subsubsection{Main frame and feed hopper}

The main frame was constructed from hollow square steel. The feed hopper was made from galvanized iron sheets to deliver raw tomatoes with average capacity $23 \mathrm{~kg}$ into the chopping part via gravity.

\subsubsection{Fruit cutting mechanism}

The cutting mechanism composed of non-sharp cutting bars, cutting rotor shaft and cuboid box. The cutting bars were made of mild steel flat bars; the length, width and thickness were 120,50 and $8 \mathrm{~mm}$, respectively. The cutting rotor shaft had $20 \mathrm{~mm}$ diameter and $450 \mathrm{~mm}$ length and mounted between two ball bearings at ends. A cuboid outer box was provided over the entire length of rotor shaft to constitute the cutting chamber.

\subsubsection{Delivery chute}

The end of the chopping section was welded into a trapezoidal chute which was equipped to easily transfer cut tomatoes into the separating drum. The slope of this chute to the horizontal was $48^{\circ}$, and the height was $440 \mathrm{~mm}$.

\subsubsection{Seed separating mechanism}

The perforated separating drum was made out of perforated galvanized steel with $1.25 \mathrm{~mm}$ thickness and round perforations. Three identical drums were manufactured with $500 \mathrm{~mm}$ diameter but were different in the holes diameter. The holes diameters for the fabricated drums were 4,5 and $6 \mathrm{~mm}$, and the distribution of holes was about 3,2 and $1 \mathrm{mesh} / \mathrm{cm}^{2}$, respectively. Each drum was fastened via using riveted joints to two circular frames, welded into a rotary shaft and positioned at two ends of the shaft. Furthermore, to allow to chopped pulped tomatoes to flow out the machine, the rotor shaft inclined $19^{\circ}$ to the horizontal and in the direction of pulp discharge outlet. The upper external part of the drum was equipped with a galvanized steel cover. The lower cover bottom was sloped down to the seed outlet $\left(9^{\circ}\right.$ to the horizontal). A perforated plastic pipe, was installed along on the inner surface of the upper cover to drain water on the internal walls of the separating chamber

After chopped tomatoes were transferred to the separating drum, the seeds under the influence of centrifugal force of the rotating drum passed through the drum openings and settled on the inner walls of the separating chamber. Simultaneously and as a consequence of the continuous flowing 
of water from the plastic pipe over the walls, extracted seeds easily slide with water to flow out the machine through seed outlet; chopped pulped tomatoes flowed out the pulp discharge outlet when the drum rotational.

\subsubsection{Power transmission systems}

The cutting rotor shaft was driven by a $0.37 \mathrm{~kW}(0.5 \mathrm{hp})$, single-phase $1400 \mathrm{rpm}$ electric motor that was connected to a gear box (reduction ratio 56:1). A drive pulley $(\phi 140 \mathrm{~mm})$, a driven pulley $(\phi 60 \mathrm{~mm})$ and a Vshape belt were equipped to obtain the speed of $60 \mathrm{rpm}(0.20 \mathrm{~m} / \mathrm{s})$ for the cutting shaft. The separating drum was powered via a $0.75 \mathrm{~kW}(1 \mathrm{hp})$, three-phase $1400 \mathrm{rpm}$ electric motor. A constant drive pulley $(100 \mathrm{~mm})$ with different combination of driven pulleys and V-belts were utilized on the drum rotor shaft to get the desired drum rotational speed.

\subsection{Performance evaluation for the extracting machine}

The experimental factors, assigned to perform the technical evaluation, were: Drum speed $(10.48,11.79,13.10,14.40$ and $15.71 \mathrm{~m} / \mathrm{s}$ (400, 450, 500, 550 and $600 \mathrm{rpm}$, respectively)); Feeding rate (90, 120, 150 and 180 $\mathrm{kg} / \mathrm{h}$ ); and Drum with holes diameter (4, 5 and $6 \mathrm{~mm}$ ).

\subsubsection{Extractor productivity}

The extractor productivity was computed by Eq. (1), (Atef $\boldsymbol{e t}$ al., 2008). The mass of cleaned extracted seeds was measured by weighting the seeds amount flowed out the seed outlet after cleaning from the tiny crushed pulp adhered to seeds. The time interval between the beginning of feeding unprocessed tomatoes into the machine and no seeds flowing out of the seed outlet was the extracting time.

$$
E_{p}=\frac{M_{c e}}{T_{e}} \times \frac{60}{10^{3}}
$$

Where:

$$
\begin{aligned}
& \mathrm{E}_{\mathrm{p}}=\text { extractor productivity, } \mathrm{kg} / \mathrm{h} ; \\
& \mathrm{M}_{\mathrm{ce}}=\text { mass of cleaned extracted seeds at seed outlet, } \mathrm{g} ; \\
& \mathrm{T}_{\mathrm{e}}=\text { extracting time, min. }
\end{aligned}
$$

\subsubsection{Extractor efficiency}

The extractor efficiency was determined by Eq. (2), (Balakrishnan $\boldsymbol{e t}$ al., 2006). The mass of lost seeds composed of both seeds adhered to the separating chamber and seeds adhered to the crushed pulped tomatoes at the pulp discharge outlet. Thus, two procedures were followed to collect 
the lost seeds. The first one was that removing the cover of the separating mechanism and using tape water to collect seeds adhered to the cover, drum and crushing unit. The second one was that immersing the crushed pulped tomatoes in a water tank and sieving out the seeds from the tank.

$$
\eta_{\mathrm{e}}=\frac{\mathrm{M}_{\mathrm{ce}}}{\mathrm{M}_{\mathrm{ce}}+\mathrm{M}_{\mathrm{L}}} \times 100
$$

Where:

$$
\begin{aligned}
& \eta_{\mathrm{e}}=\text { extractor efficiency, } \% \\
& \mathrm{M}_{\mathrm{L}}=\text { mass of the collected seed losses, } \mathrm{g} .
\end{aligned}
$$

\subsubsection{Seed purity}

The seed purity was estimated by using the following relationship (ElIraqi et al., 2012). The tiny crushed pulp was isolated from seeds by immersing the whole seed sample flowed out seed outlet in a water tank, so that the tiny crushed pulp floated on the water surface due to its light weight and was sieved out from the tank.

$$
\mathrm{P}_{\mathrm{s}}=\frac{\mathrm{M}_{\mathrm{ce}}}{\mathrm{M}_{\mathrm{ce}}+\mathrm{M}_{\mathrm{tcp}}} \times 100
$$

Where:

$$
\begin{aligned}
\mathrm{P}_{\mathrm{s}} & =\text { seed purity, } \% \\
\mathrm{M}_{\mathrm{tcp}} & =\text { mass of tiny crushed pulp adhered to seeds at seed outlet, } \mathrm{g} .
\end{aligned}
$$

\subsubsection{Seed losses percentage}

Seed losses ( $\left.\mathrm{S}_{\mathrm{L}}, \%\right)$ were calculated by Eq. (4), (AL-Gaadi et al., 2011).

$$
\mathrm{S}_{\mathrm{L}}=\frac{\mathrm{M}_{\mathrm{L}}}{\mathrm{M}_{\mathrm{ce}}+\mathrm{M}_{\mathrm{L}}} \times 100
$$

\subsubsection{Total specific energy consumption}

The ratio between the total power consumption $(\mathrm{kW})$ and the extractor productivity $(\mathrm{kg} / \mathrm{h})$ was defined as the total specific energy consumption (SEC, kW.h/kg). Based on the equation developed by (Gieck and Gieck, 2006), the total power, consumed in cutting tomato fruits and separating seeds, was computed as in the succeeding equation:

Where:

$$
\mathrm{P}_{\mathrm{t}}=\left(\left[\left(\mathrm{I}_{1} \times \mathrm{v}_{1}\right)+\left(\mathrm{I}_{2} \times \mathrm{v}_{2}\right)\right] \times \eta \times \cos \theta\right) \times 10^{3}
$$

$\mathrm{P}_{\mathrm{t}} \quad=$ total power consumption, $\mathrm{kW}$;

$\mathrm{I}_{1} \quad$ = line current strength for separating motor, Amperes;

$\mathrm{V}_{1}$ = potential difference for separating motor, Voltage; 
$\mathrm{I}_{2}$ = line current strength for crushing motor, Amperes;

$\mathrm{V}_{2}$ = potential difference for crushing motor, Voltage;

$\eta \quad=$ mechanical efficiency assumed (80\%);

$\cos \theta=$ power factor equaling 0.64 .

\subsubsection{Germination percentage}

The purpose of the germination test was to find how the mechanical extraction of tomato seed could influence over germinability of seeds in comparison to the manual technique (control). To perform the test, 100 seeds were positioned equidistance from each other on a filter paper, dampened in water, in a Petri dish. The Petri dishes were then placed in an incubator at $29^{\circ} \mathrm{C}$ for 14 days (ISTA, 1976). Between the fourth and fourteenth day, the incubator was checked daily, the germinated seeds per a Petri dish were counted, and the germination percentage (\%) was determined by dividing the number of germinated seeds by the whole number of seeds in the sample.

\subsubsection{Overall extraction cost}

Validating the feasibility of ownership the tomato seed extracting machine in terms of cost was accomplished by carrying out a comparison between mechanical and manual extraction charges. Moreover, the financial value of chopped pulp tomatoes, produced from the extractor, was considered as a by-product, assessed and subtracted from the total cost of mechanical extraction. In contrast, there were no by-products of the manual extraction system because all components of tomatoes after fermentation lost during washing step except seeds.

According to (Soliman, 2007), the overall mechanical extraction cost $(\mathrm{LE} / \mathrm{h}$ ) was estimated by addition of fixed cost items (depreciation charge, interest charge, cost of taxes, insurance and housing) and variable cost items (repair and maintenance cost, energy cost, water cost, labor cost). In parallel, the pulp tomato revenue (PTR, LE/h) was assessed by multiplying the extractor capacity of pulp tomato $(90 \mathrm{~kg} / \mathrm{h})$ by its unit price $(0.10 \mathrm{LE} / \mathrm{kg})$. Given that the worker productivity of raw tomato was $38 \mathrm{~kg} / \mathrm{h}$ according to field data, total number of workers $(\mathrm{N})$, needed to handle the same amount of tomato extracted mechanically, was assigned 4 workers per day. Therefore, the computation of total manual extraction cost (LE/h) was estimated by multiplying $\mathrm{N}$ by hourly worker wage. 


\section{RESULTS ANDDISCUSSION}

\subsection{Extractor productivity}

Fig. (2) depicts the effect of drum speed, feeding rate and drum with holes diameter on the extractor productivity. Statistical analysis demonstrated that the mean of machine productivity was $4.37,5.02,5.79,6.46$ and 7.79 $\mathrm{kg} / \mathrm{h}$ at the drum speeds of $10.48,11.79,13.10,14.40$ and $15.71 \mathrm{~m} / \mathrm{s}$, respectively, was $3.90,5.25,6.68$ and $7.71 \mathrm{~kg} / \mathrm{h}$ at the feeding rates of 90 , 120,150 and $180 \mathrm{~kg} / \mathrm{h}$, respectively and was $5.71,6.02$ and $5.93 \mathrm{~kg} / \mathrm{h}$ at the drum with holes diameters of 4,5 and $6 \mathrm{~mm}$, respectively. It can be seen from these derived data that each rise in whether the cylinder speed or the feeding rate was translated into steady progress in the productivity numbers, while altering the drum mesh from 5 to $6 \mathrm{~mm}$ led to a reduction in the extractor productivity.
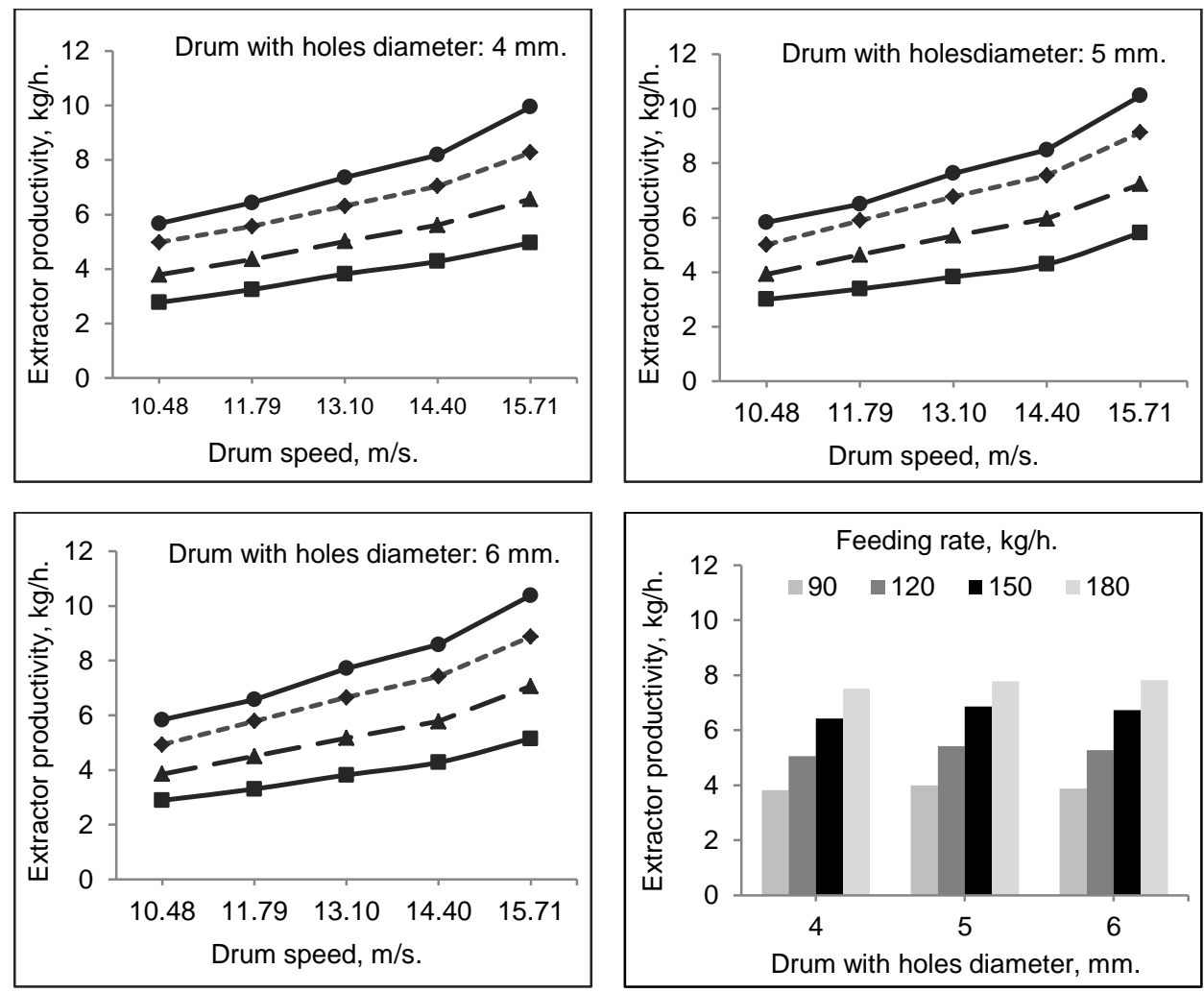

Feeding rate, $\mathrm{Kg} / \mathrm{h}$.

$\rightarrow-90$

$\rightarrow-120$

$\rightarrow-150$

$\longrightarrow 180$

Fig. (2): Influence of drum speed, feeding rate and drum with holes diameter on the extractor productivity. 
These results may be because of that at higher drum speeds and feeding rates the productivity enlarged due to increasing the centrifugal force and the amount of tomato fruits supplied to the equipment per time, respectively. However, the machine productivity at $6 \mathrm{~mm}$ mesh was lower than at $5 \mathrm{~mm}$ mesh was due to that the opening of $6 \mathrm{~mm}$ enabled seeds to flow out with more attached tiny crushed pulp which enhanced higher adhesiveness between the separated seed and the internal surface of the drum cover and declined the extractor productivity. In a summary, the most acceptable number of the extractor productivity, for the economic operation of the machine, was $9.12 \mathrm{~kg} / \mathrm{h}$ at $51.71 \mathrm{~m} / \mathrm{s}$ drum speed, 150 $\mathrm{kg} / \mathrm{h}$ feeding rate and $5 \mathrm{~mm}$ drum mesh.

\subsection{Extractor efficiency}

Figs. (3) shows the relationship between drum speed and the extractor efficiency at different feeding rates from 90 to $180 \mathrm{~kg} / \mathrm{h}$ for drum with holes diameters of 4,5 and $6 \mathrm{~mm}$, respectively. It was noticed that the extractor efficiency became greater with an increment in the drum speed as a consequence of centrifugal force (Myers and Monroe, 1972). The more centrifugal force impacts on crushed tomatoes, the more opportunity for seeds to leave other tomato parts, pass through drum perforations and increase the efficiency. It was observed that increasing the drum speed from $10.48 \mathrm{~m} / \mathrm{s}$ to $15.71 \mathrm{~m} / \mathrm{s}$, the extractor efficiency as an average was increased from $78.45 \%$ to $91.17 \%$, respectively.

It is also clear from the Fig. (3) that expanding the feeding rates up to 150 $\mathrm{kg} / \mathrm{h}$ at various drum speeds and drum with holes diameters resulted in an essential improvement in the extractor efficiency. The overall average of extractor efficiency was $82.59,84.86$ and $88.09 \%$ at feeding rates of 90 , 120 and $150 \mathrm{~kg} / \mathrm{h}$, respectively. On the contrary, after increasing the feeding rate to $180 \mathrm{~kg} / \mathrm{h}$, the extractor efficiency as an average was declined to $87.11 \%$. These obtained results could be explained based on that each increment in the mass of chopped tomatoes per time means not only a greater number of seed contained within that mass but also higher centrifugal force so that more seed could be extracted, increasing the extractor efficiency. However, the expansion in the mass of the material inside the separating cylinder is relative to some other variables, such as the cylinder inner area, the number of drum mesh per $\mathrm{cm} 2$ and time; thus 
the additional load over $150 \mathrm{~kg} / \mathrm{h}$ in the drum, having a constant area and mesh per unit area, could lead to impede the stream of seed through drum holes because of low space being available for materials motion in the drum and increase seed losses (Abd El-Tawwab et al., 2012).
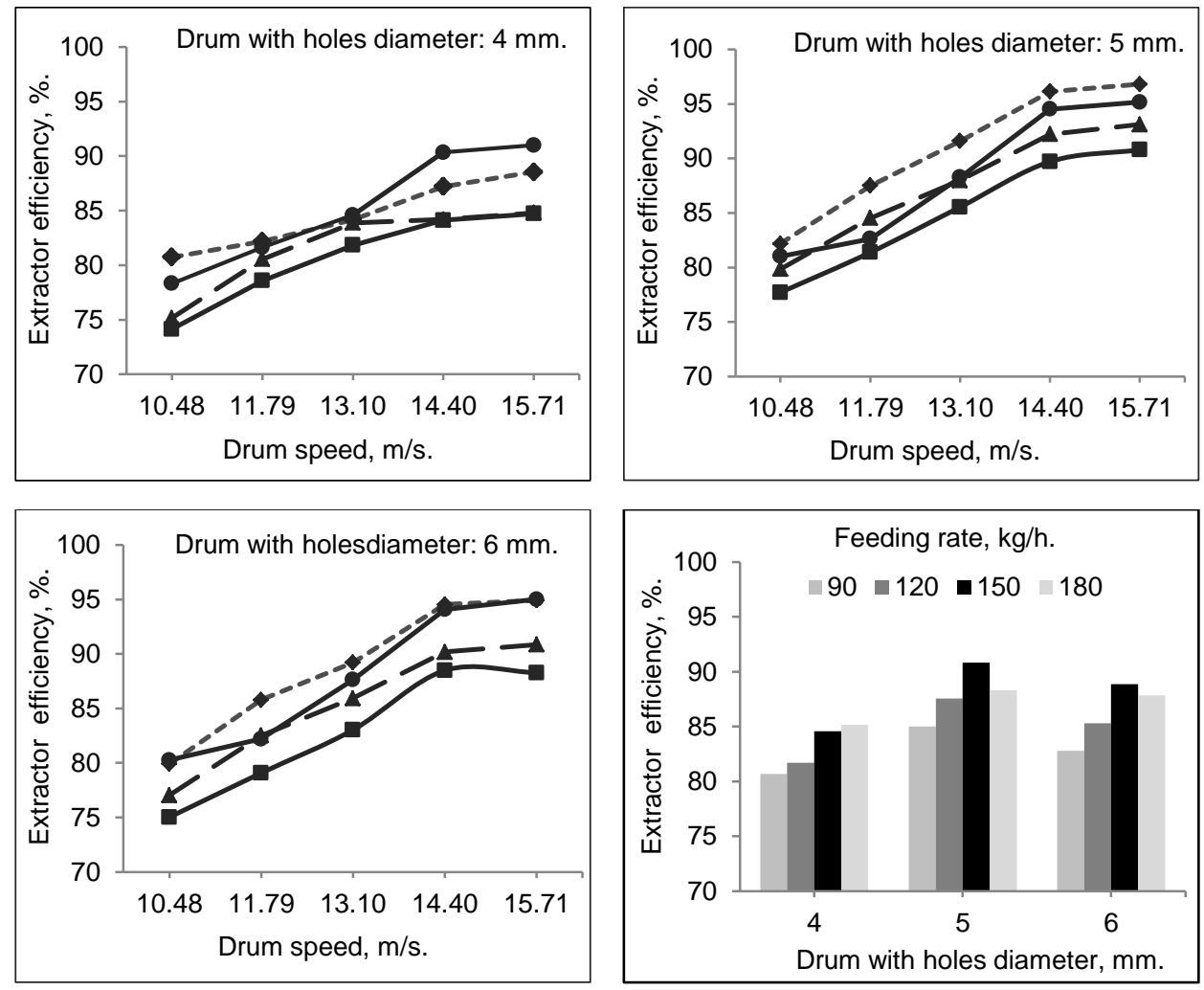

Feeding rate, $\mathrm{Kg} / \mathrm{h}$.

$\longrightarrow-90$

$\rightarrow-120$

$\rightarrow-150$

$\longrightarrow 180$

Fig. (3): Influence of drum speed, feeding rate and drum with holes diameter on the extractor efficiency.

Using drums with holes diameter of 4,5 and $6 \mathrm{~mm}$, the extractor efficiency was ranged from 74.14 to $90.99,77.71$ to 96.80 and 75.02 to $95.02 \%$, respectively. Data clarify that the lowest efficiency was at $\phi 4$ $\mathrm{mm}$ because the drum hole size was not large enough and intensified the friction between flowed seed and the boundary of drum hole with the result that the separated seed could not flow out easily, decreasing the extractor efficiency. Meanwhile, the highest value was at $\phi 5 \mathrm{~mm}$ since the opening area was more appropriate that seed could stream with less friction, increasing the extractor efficiency. Although the area of $6 \mathrm{~mm}$ 
mesh was greater than the area of $5 \mathrm{~mm}$ mesh, the extractor efficiency for the drum of $6 \mathrm{~mm}$ was lower than the drum of $5 \mathrm{~mm}$ due to the same reasons as discussed in the case of the extractor productivity. Accordingly, the highest extractor efficiency (96.80\%) was obtained using $15.71 \mathrm{~m} / \mathrm{s}(600 \mathrm{rpm}), 150 \mathrm{~kg} / \mathrm{h}$ and $5 \mathrm{~mm}$ for the drum speed, feeding rate and drum with holes diameter, respectively.

\subsection{Seed purity}

The relationships among the investigated operating parameters and the seed purity are plotted in Fig. (4). The mean of seed purity increased from 91.53 to $93.20 \%$ when the drum speed increased from 10.48 to 15.71 $\mathrm{m} / \mathrm{s}$, respectively. At the higher drum speed a better distribution of drained water in the separating chamber was observed owing to high collision between dropped water and the rotating drum.
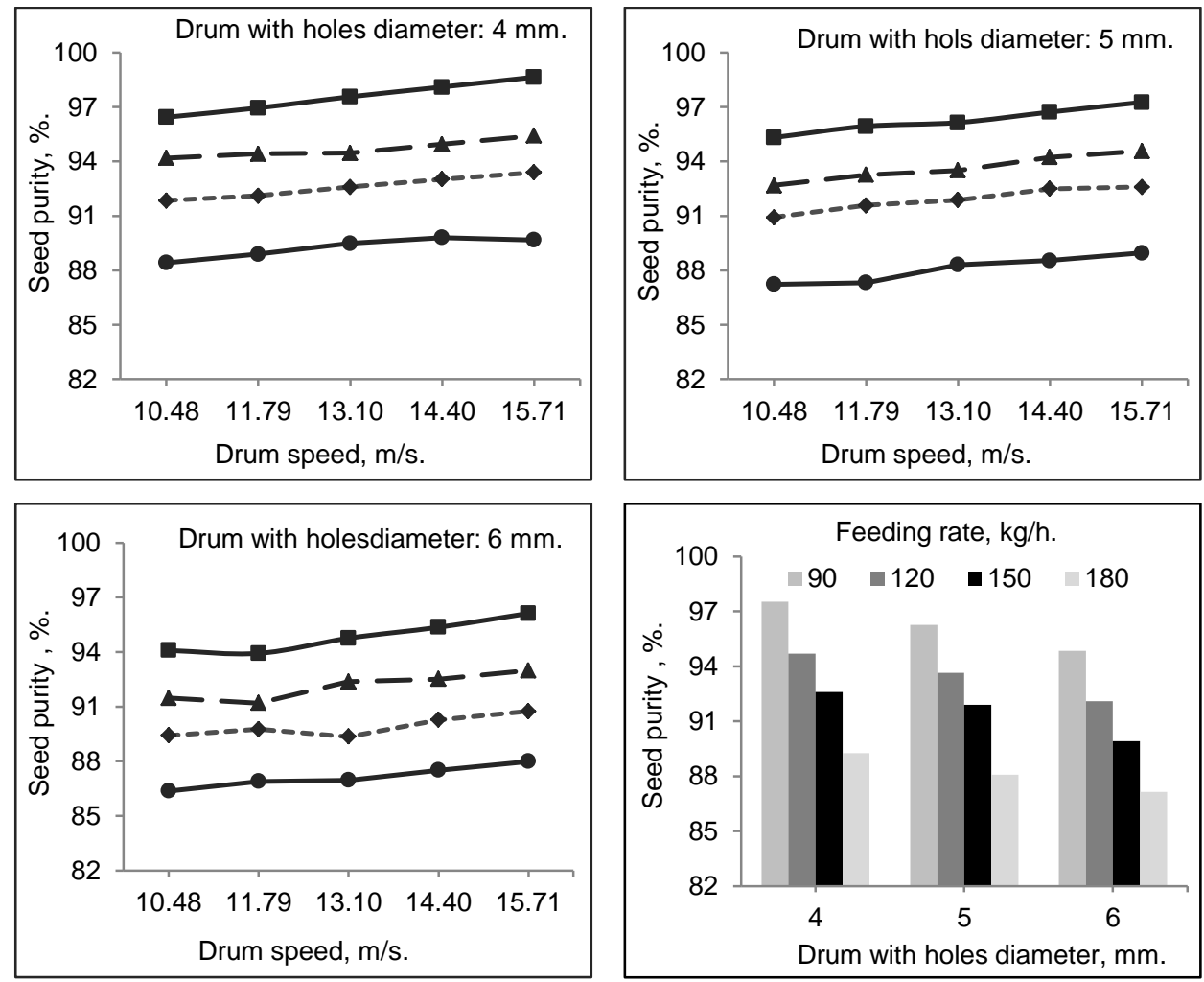

Feeding rate, $\mathrm{Kg} / \mathrm{h}$.

$\longrightarrow-90$

$\rightarrow-120$

$\rightarrow-150$

$\longrightarrow 180$

Fig. (4): Influence of drum speed, feeding rate and drum with holes diameter on the seed purity. 
Meanwhile, the mean of seed purity declined from 96.22 to $88.16 \%$ as feeding rates increased from 90 to $180 \mathrm{~kg} / \mathrm{h}$, respectively because the more tomatoes were fed to the machine per unit time, the more tiny crushed pulp adhered to extracted seeds. When the mesh diameters increased from 4 to $6 \mathrm{~mm}$, the mean of seed purity decreased from 93.52 to $91.00 \%$ due to that the lowest diameter reduced the passed tiny crushed pulp and maximize the seed purity, and vice versa.

Briefly, the result of $92 \%$ seed purity (at $14.40 \mathrm{~m} / \mathrm{s}$ drum speed, $150 \mathrm{~kg} / \mathrm{h}$ feeding rate and $5 \mathrm{~mm}$ drum mesh diameter) was found to be the most fitting for the current study.

\subsection{Seed losses percentage}

Fig. (5) represents the seed losses percentage related to the drum speed, feeding rate and drum with holes diameter.
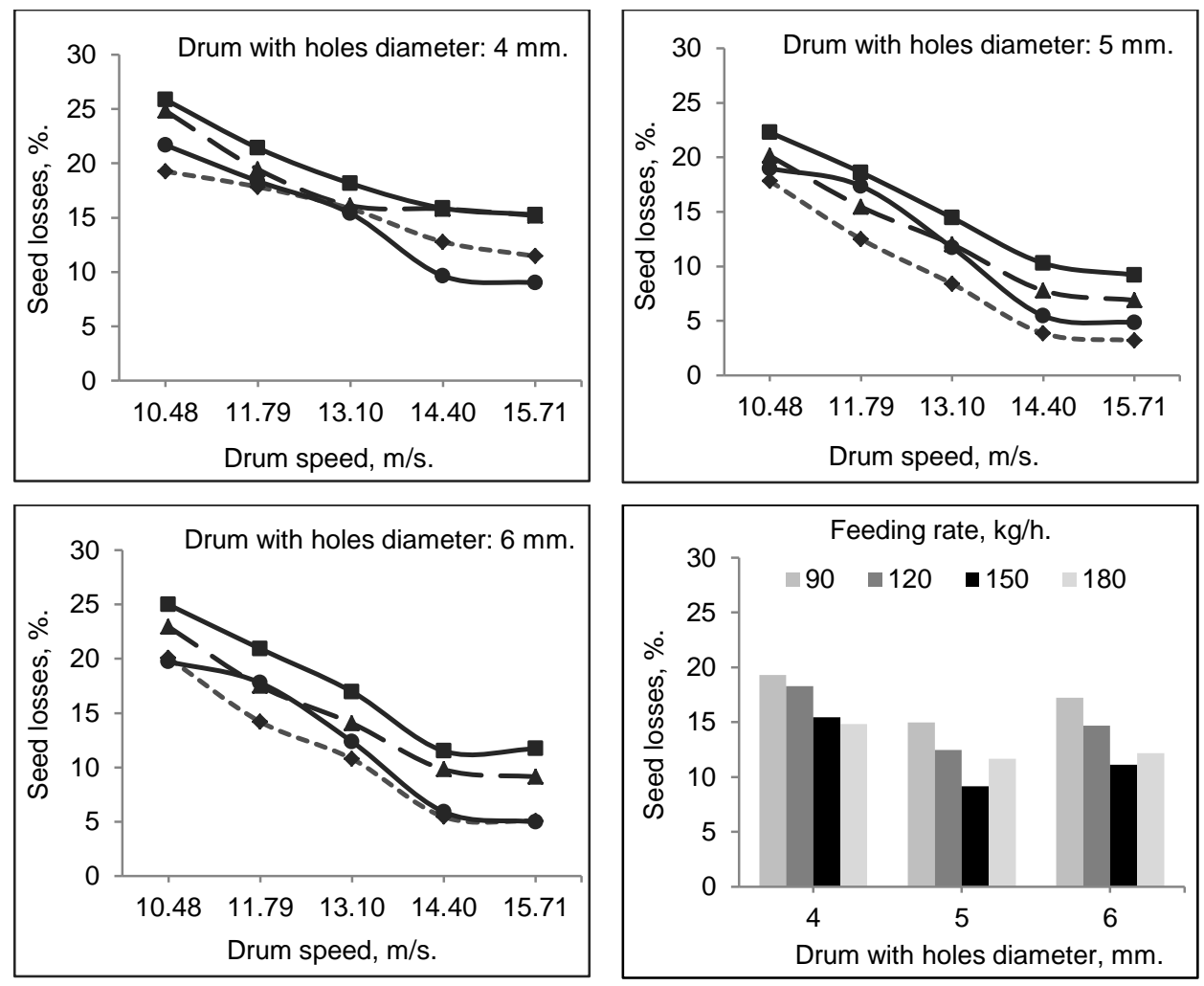

Feeding rate, $\mathrm{Kg} / \mathrm{h}$.

Fig. (5): Influence of drum speed, feeding rate and drum with holes diameter on the seed losses percentage. 
It was observed that the mean of seed losses percentage was decreased from 21.55 to $8.83 \%$ when increasing the drum speed from 10.48 to 15.71 $\mathrm{m} / \mathrm{s}$. This may be due to that the amount of extracted seeds was decreased at the lower drum speed. At the feeding rates of 90, 120, 150 and 180 $\mathrm{kg} / \mathrm{h}$, the average of seed losses percentage were 17.41, 15.14, 11.91 and $12.89 \%$, respectively. Increasing the feeding rates up to $150 \mathrm{~kg} / \mathrm{s}$ led to reduction in the lost seed owing to heightening the extracted seeds, but at the feeding rate of $180 \mathrm{~kg} / \mathrm{h}$ the extracted seeds became lower. Using the drum of $5 \mathrm{~mm}$ mesh yielded the lowest seed losses mean (12.24\%), while the highest seed losses mean was at the drum of $4 \mathrm{~mm}$ mesh (16.97\%). Hence, utilizing the drum speed of $15.71 \mathrm{~m} / \mathrm{s}$, feeding rate of $150 \mathrm{~kg} / \mathrm{h}$ and drum mesh diameter of $5 \mathrm{~mm}$ yielded the lowest seed losses percentage $(3.20 \%)$.

\subsection{Specific energy consumption (SEC)}

Fig. (6) shows that the effect of the drum speed, feeding rate and drum with holes diameter on SEC. It is clear that at the feeding rate of 90, 120, 150 and $180 \mathrm{~kg} / \mathrm{h}$, SEC as an average was $0.067,0.056,0.049$ and 0.046 $\mathrm{kW} . \mathrm{h} / \mathrm{kg}$, respectively because the machine productivity was proportional to the feeding rates (El-Iraqi et al., 2012). As the drum speed was varied from 10.48 to $11.79 \mathrm{~m} / \mathrm{s}$, the mean of SEC was raised from 0.055 to 0.057 $\mathrm{kW} . \mathrm{h} / \mathrm{kg}$ due to that the machine productivity was not adequate to significantly control the value of SEC. However, after the speed of 11.79 $\mathrm{m} / \mathrm{s}$ the SEC average gradually declined until it reached $0.049 \mathrm{~kW} . \mathrm{h} / \mathrm{kg}$ because the machine productivity was sufficient to reduce SEC. The minimum mean of SEC was at the drum mesh of $5 \mathrm{~mm}(0.053 \mathrm{~kW} . \mathrm{h} / \mathrm{kg})$, and the maximum mean was at $4 \mathrm{~mm}(0.056 \mathrm{~kW} . \mathrm{h} / \mathrm{kg})$.

\subsection{Germination percentage}

The analysis of germination tests data showed that the germination percentage of seeds, extracted mechanically, was ranged from 84.4 to $91.7 \%$, and the control seeds, extracted manually, had a germination percentage between 86.2 and $92.1 \%$. These results proof that the mechanical extraction of tomato seeds, via using the developed extractor, does not have harmful effects of the germinabilty of seeds. 

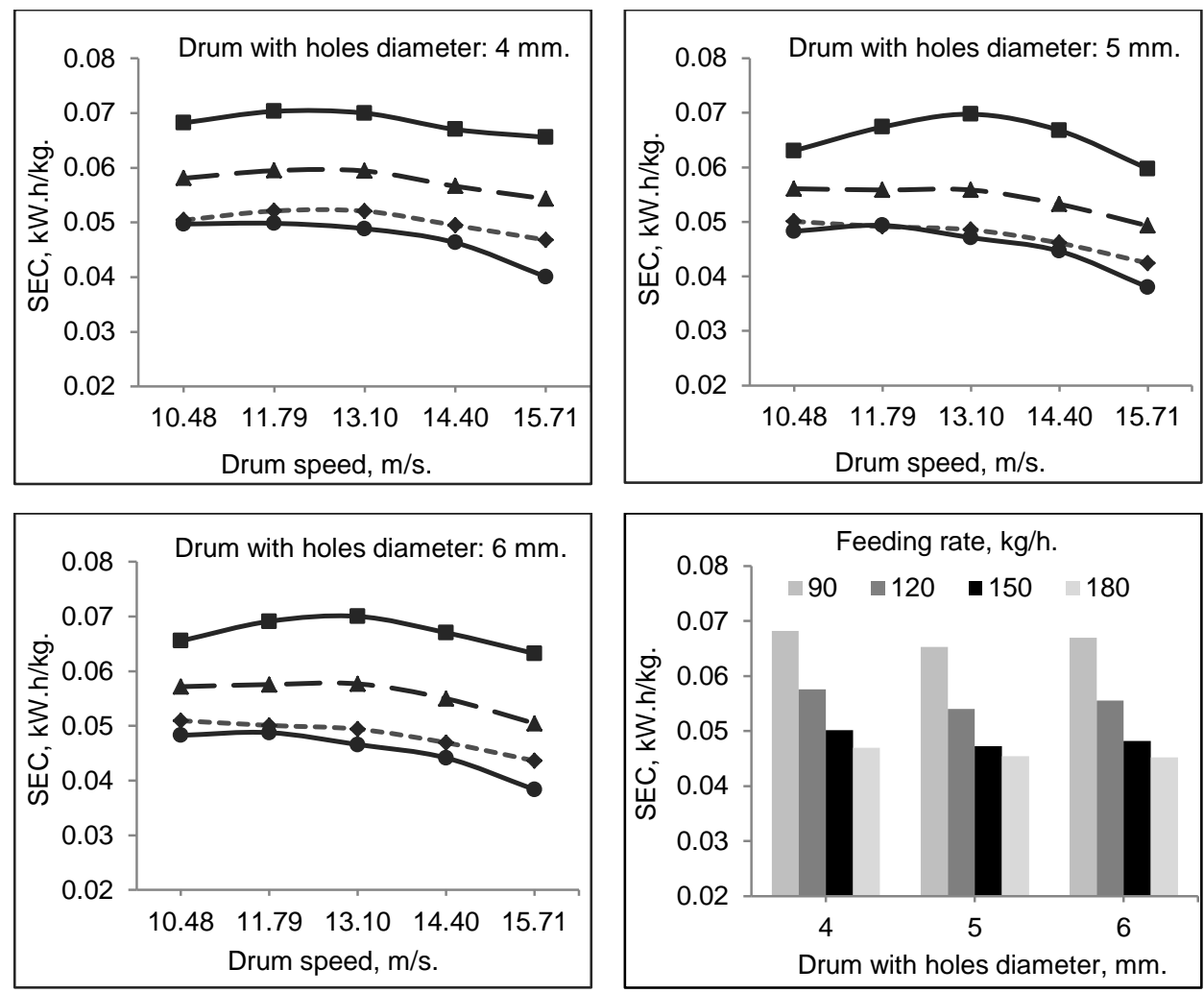

Feeding rate, $\mathrm{Kg} / \mathrm{h}$.

Fig. (6): Influence of drum speed, feeding rate and drum with holes diameter on the specific energy consumption.

\subsection{Cost analysis}

The main finding of this analysis was that the total extraction cost of the manual system rose by about 42 and $182 \%$ in comparison with the full mechanical extraction cost before and after discounting PTR, respectively. The hourly extracting cost with the mechanical method before and after including PTR and with the manual method were 18.10, 9.07 and $26 \mathrm{LE} / \mathrm{h}$, respectively. The results indicate that the mechanical extraction is more economic process than the manual extraction, particularly when the seed producers have the marketability of the pulp tomato by-product which is not accessible in the manual system. The reason may be due to that the hourly worker charge is very high, and the manual cost is primarily depended on that cost element. 


\section{SUMMARY AND CONCLUSION}

- A positive relationship was found to be between the rotational drum speed and extracting efficiency, extractor productivity and seed purity, but it was opposite with seed losses.

- The machine productivity and extracting efficiency (up to the feeding rate $150 \mathrm{~kg} / \mathrm{h}$ ) were observed to be directly proportional to feeding rates, while the contrary was true in the seed purity, energy consumption and seed losses (up to the feeding rate $150 \mathrm{~kg} / \mathrm{h}$ ).

- An inverse relation was detected between the drum with holes diameter and seed purity, seed losses (up to drum mesh of $5 \mathrm{~mm}$ ) and energy requirement (up to drum mesh of $5 \mathrm{~mm}$ ). However, positive relation was clear between the extracting efficiency and machine productivity (up to drum mesh of $5 \mathrm{~mm}$ ).

- Operating the drum at $15.71 \mathrm{~m} / \mathrm{s}(600 \mathrm{rpm})$, feeding the machine with $150 \mathrm{~kg} / \mathrm{h}$ of tomato fruits and selecting the drum mesh of $5 \mathrm{~mm}$ achieved the economic operation for the developed machine by extracting efficiency $(96.80 \%)$, extractor productivity $(9.12 \mathrm{~kg} / \mathrm{h})$, seed losses $(3.20 \%)$, seed purity $(92.00 \%)$ and energy requirement $(0.042$ $\mathrm{kW} \cdot \mathrm{h} / \mathrm{kg}$ ).

- In the mechanical extraction, the germination percentage of seeds was at ranged of 84.4-91.7\% which was similar to the germination percentage of manual extraction (between 86.2 and $92.1 \%$ ).

- In terms of the total cost needed to extracting tomato seeds, the cost of manual process rose by about 42 and $182 \%$ in comparison with the cost of mechanical system before and after discounting PTR, respectively.

\section{REFERENCES}

Abd El-Tawwab, I.M.; T.R. Owies and U.A. Kaddour (2012). Design and performance evaluation of multi-germ beet-seeds grading machine. J. Soil Sci. and Agric. Eng., Mansoura University, 3 (4): 512-537. 
AL-Gaadi, K.A, S.A. Marey ans I.F. Sayed-Ahmed. (2011). Development and performance evaluation of a summer squash seed extracting machine. Middle-East J. of Sci. Res., 7 (3): 352-361.

Balakrishnan M., V. Thirupathi and V. V. Sree Narayanan (2006). Development and Testing of a Chilli Seed Extractor. Agric. Mech. Asia, Africa, and Latin America, 37 (4): 46-48.

El-Iraqi, M.E.; S.E. El Khawaga and T.R. Awais (2012). Design and fabrication of an extraction machine for tomato seeds. M. J. Agric. Eng., 29: 39-60.

Food and Agriculture Organization (FAO), (2016). Statistical Databases. Available at http://faostat.fao.org/.

Gieck, K. and R. Gieck (2006). Engineering Formulas. Textbook, $8^{\text {th }}$ ed., McGraw-Hill Education.

Gregg, B.R. and G.L. Billups (2010). Seed Conditioning. Technology Part A: Advanced-level Information for Managers, Technical Specialists, and Professionals. Handbook, $1^{\text {st }}$ ed., vol. 2.

International Seed Testing Association (ISTA), (1976). International rules for seed testing. Seed Science and Technology 4: 51-177.

Kailappan, R.; P.K. Baig; N. Varadharaju; K. Appavu and V. Krishnasamy (2005). Fabrication and testing of tomato seed extractor. Agric. Mech. Asia, Africa, and Latin America, 36 (2): 4648.

Kalra, M.S.; and R. Srivastava and K.K. Kaul (1983). Development of tomato seed extractor. J. of Agric. Eng., 20: 183-186.

McCormarck, J. H. (2010). Tomato Seed Production. An Organic Seed Production Manual for Seed Growers in the Mid-Atlantic and Southern U.S. Technical Bulletin, pp. 1-16.

Myers, A.L. and G. E. Monroe. (1972). Centrifuge for coffee bean surface water removal. Transactions of the ASAE, 15(2):308-309.

Soliman, I. (2007). Agricultural mechanization systems management. $1^{\text {st }}$ edition, Dar Elfikr Elarabi Press, Egypt. 


\section{الملخـص العربــ \\ تصنيع آلة لاستخلاص بذور ثمار الطماطم}

* أحمد مصطفى إبراهيم سليمان، **ممود النونو، **مبارك محمد مصطفى، ***/لأمين عارف

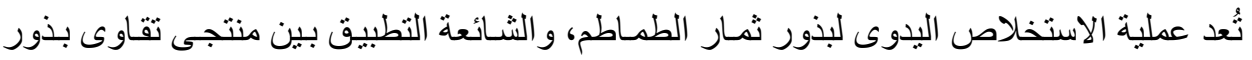

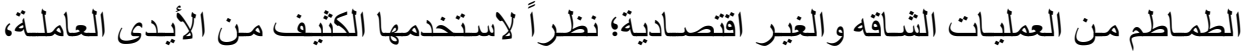

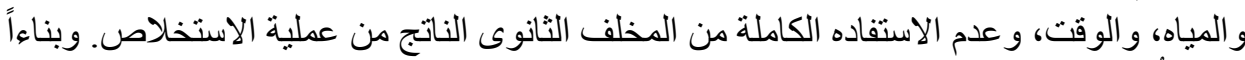

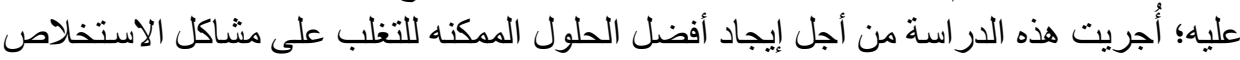

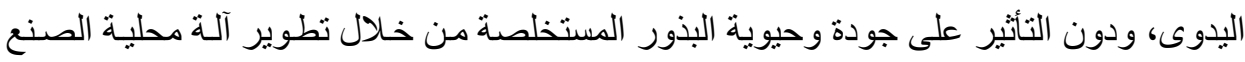

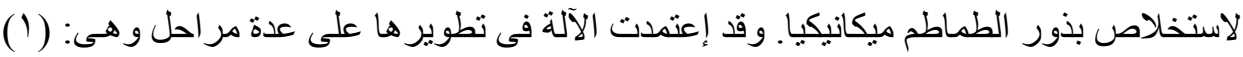

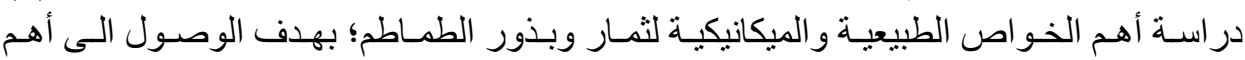

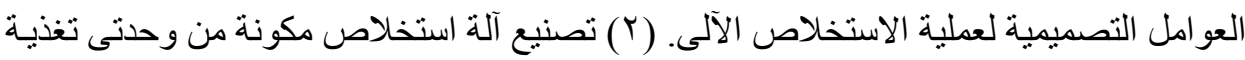

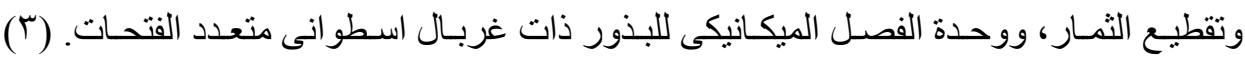

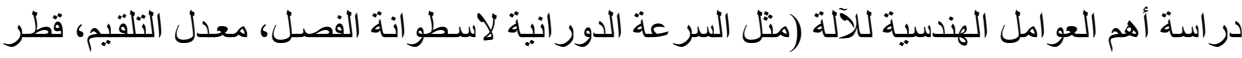

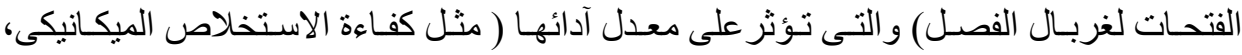

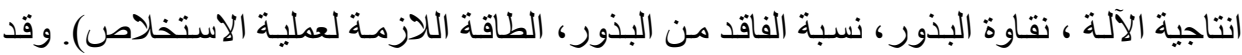

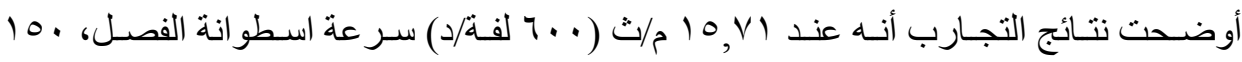

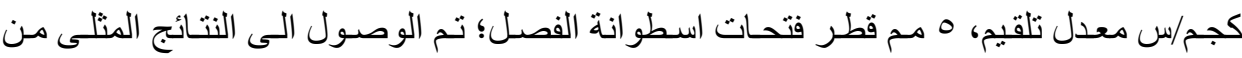

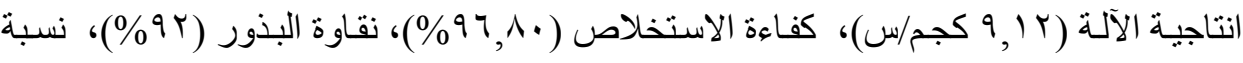

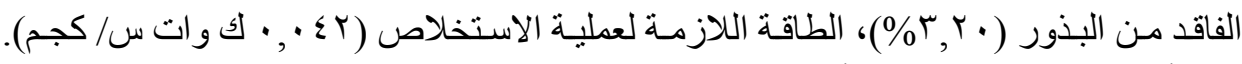

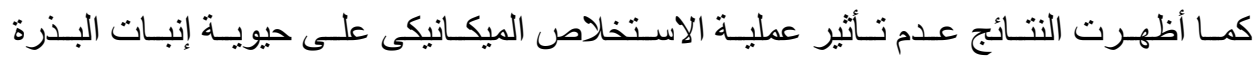

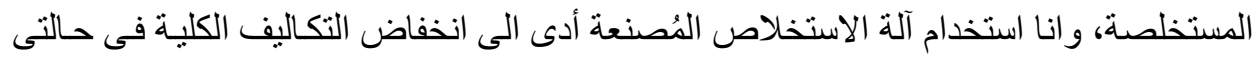

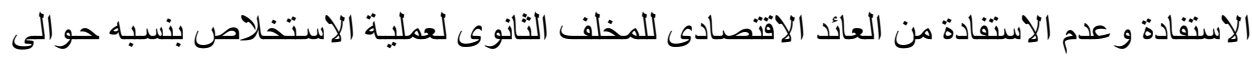

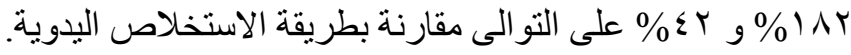

" باحث مساعد - معهل بحوث الهندسة الزراعية ـ مركز البحوث الزراعية.

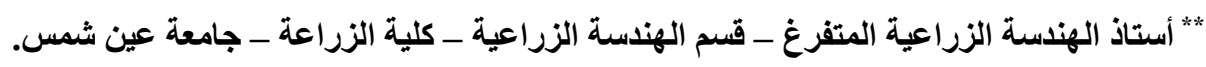

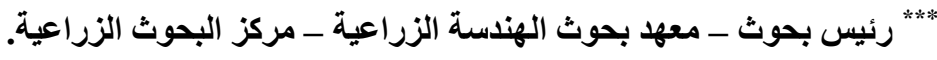

